\title{
FORMAÇÃO INICIAL DE PROFESSORES INDÍGENAS: AÇÕES DESENVOLVIDAS NO ESTADO DO PARANÁ
}

\author{
FORMACIÓN INICIAL DE PROFESORES INDÍGENAS: ACCIONES \\ DESARROLLADAS EN EL ESTADO DE PARANÁ
}

\author{
INITIAL EDUCATION OF INDIGENOUS TEACHERS: ACTIONS DEVELOPED IN \\ THE STATE OF PARANÁ
}

\author{
Maria Christine Berdusco MENEZES ${ }^{1}$ \\ Rosangela Celia FAUSTINO ${ }^{2}$ \\ Maria Simone Jacomini NOVAK ${ }^{3}$
}

RESUMO: Os anos de 1970 tem como marco histórico o início do processo de formação de professores indígenas, formando monitores bilíngues. A partir da Constituição de 1988 e do Decreto $\mathrm{n}^{\mathrm{o}} 26$ de 1991, a política da educação escolar indígena passa a ser de responsabilidade do Ministério da Educação, possibilitando a formulação de uma vasta legislação específica para esta modalidade de ensino, entre elas Diretrizes que definem e orientam programas e cursos específicos para a formação de professores indígenas. Nesse texto, cujo objetivo é analisar os avanços e desafios para a formação inicial de professores indígenas, apresentamos as ações desenvolvidas no estado do Paraná para essa política, a partir de pesquisa qualitativa e quantitativa de cunho bibliográfico e documental. Verificamos que o estado tem avançado, entretanto, ainda há necessidade de aumentar os números de professores formados em nível superior para atuar nas escolas indígenas, bem como a oferta de licenciaturas específicas e interculturais que possibilitem a formação integral do sujeito indígena em seus aspectos de territorialidade, cultura, língua, metodologias, concepções de ensino e de aprendizagem que considerem os modos próprios de aprender, inter-relacionados com os etnosaberes.

PALAVRAS-CHAVE: Formação inicial de professores indígenas. Paraná. Políticas. Avanços e desafios.

RESUMEN: La década de 1970 vio el inicio del proceso de formación de profesores indígenas, monitores bilingües. Con la Constitución de 1988 y el Decreto $n^{\circ} 26$ de 1991, la política de educación escolar indígena pasa a la responsabilidad del Ministerio de Educación, permitiendo la formulación de una amplia legislación hacia esta enseñanza, entre ellos lineamientos que definen y orientan programas y cursos para la formación de profesores indígenas. En este texto, el objetivo es analizar los avances y desafios para la

${ }^{1}$ Universidade Estadual de Maringá (UEM), Maringá - PR - Brasil. Professora no Programa de Pós-Graduação em Educação e no Programa de Pós-Graduação em Agroecologia. Doutorado em Educação (UEM). ORCID: https://orcid.org/0000-0002-3097-5242.E-mail: mcbmenezes@uem.br

${ }^{2}$ Universidade Estadual de Maringá (UEM), Maringá - PR - Brasil. Professora e Chefe do Departamento de Teoria e Prática da Educação. Doutorado em Educação (UFSC). ORCID: https://orcid.org/0000-0002-00945528. E-mail: rcfaustino@uem.br

${ }^{3}$ Universidade Estadual do Paraná (UEM), Paranavaí - PR - Brasil. Professora Adjunta no Colegiado de Pedagogia. Doutorado em Educação (UEM). ORCID: https://orcid.org/0000-0002-3820-6579. E-mail: maria.novak@unespar.edu.br

RIAEE - Revista Ibero-Americana de Estudos em Educação, Araraquara, v. 16, n. esp. 1, p. 910-925, mar. 2021. e-ISSN: 1982-5587 
formación inicial de maestros indígenas. Presentamos las acciones desarrolladas en el estado de Paraná/Brasil para esta formación, con una investigación cualitativa y cuantitativa de carácter bibliográfico y documental. Observamos que el estado ha avanzado, sin embargo, aún existe la necesidad de incrementar el número de docentes capacitados en un nivel superior para trabajar en escuelas indígenas, así como la oferta de titulaciones específicas e interculturales hacia la formación integral del sujeto indígena en sus aspectos de territorialidad, cultura, lenguaje, metodologías, concepciones de la enseñanza y el aprendizaje que consideren las formas adecuadas de aprendizaje, interrelacionadas con los etnosaberes.

PALABRAS CLAVE: Formación inicial de docentes indígenas. Paraná. Políticas. Avances y retos.

ABSTRACT: The 1970s saw the beginning of the process of initial formation of indigenous teachers, forming bilingual monitors. As of the 1988 Constitution and Decree No. 26 of 1991, the policy of indigenous school education becomes the responsibility of the Ministry of Education, enabling the creation of a wide and specific legislation for this type of teaching, among them Guidelines that define and guide the formulation of specific programs and courses aimed at the training of indigenous teachers. In this text, which seeks to analyze the advances and challenges of the initial training of indigenous teachers, we present the actions developed in the state of Paraná based on qualitative and quantitative research of bibliographic and documentary nature. We note that the state has advanced, however, there is still a need to increase the number of teachers trained at a higher level to work at indigenous schools, as well as the offer of specific and intercultural teaching degrees that enable the wholesome formation of the indigenous individual in their aspects of territory, culture, language, methodologies and conceptions of teaching and learning that consider the proper ways of learning in relation to ethnographic knowledge.

KEYWORDS: Initial education of indigenous teachers. Paraná. Policies. Advances and challenges.

\section{Introdução}

O texto aborda a temática da Formação Inicial de Professores Indígenas destacando os avanços e desafios no processo de formação docente indígena no estado do Paraná, a partir da Constituição de 1988 e leis infraconstitucionais. As reflexões resultam de ações do Laboratório de Arqueologia, Etnografia e Etno-história da Universidade Estadual de Maringá, que desde 1996, tem uma equipe interdisciplinar de pesquisadores que estudam temas relacionados aos povos indígenas no Paraná, bem como desenvolve projetos de formação de professores indígenas, em consonância com as demandas indígenas.

O processo formativo para a docência indígena no Paraná teve início nos anos de 1970, sob a coordenação da Fundação Nacional do Índio (FUNAI), como ocorria em diferentes estados brasileiros (OLIVEIRA, 1999). Conforme pontua Faustino (2006), os 
indígenas territorializados no Paraná participaram da primeira turma (1970-1971) do curso de Formação de Monitores Bilíngues, Projeto Clara Camarão, desenvolvido na Terra Indígena Guarita, localizada no estado do Rio Grande do Sul, organizado e coordenado pela agência missionária Summer Institute of Linguistic (SIL), conveniada com a FUNAI. O objetivo era formar monitores indígenas bilíngues que atuariam como tradutores em sala de aula até que as crianças aprendessem o português e dominassem o código da linguagem escrita, isto é, para atuação nos anos iniciais do ensino fundamental (MENEZES, 2016).

Logo após a promulgação da Constituição de 1988 que normatizou os direitos dos povos indígenas, entre eles o direito de utilizar a língua materna e os processos próprios de aprendizagem na educação básica, uma ampla legislação infraconstitucional, que inclui resoluções, decretos, diretrizes, pareceres e referenciais foi publicada visando regulamentar as ações na organização da educação escolar indígena.

Em 1991, o Decreto $n^{0} 26$ atribuiu ao Ministério da Educação a "competência para coordenar as ações referentes à Educação Indígena” (BRASIL, 1991), ou seja, a educação escolar indígena passou a ser laica, sendo proibida sua condução por ordens religiosas. A Portaria Interministerial n. 559, publicada no mesmo ano, prescreve o dever do Estado e define em seu Art. $1^{\circ}$ "Garantir às comunidades indígenas uma educação escolar básica de qualidade, laica e diferenciada, que respeite e fortaleça seus costumes, tradições, língua, processos próprios de aprendizagem e reconheça suas organizações sociais" (BRASIL, 1991).

O Parecer $n^{\circ}$. 14/99 afirma que havia, no período, um grande número de professores indígenas sem a formação convencional em magistério; tinham o domínio dos conhecimentos da cultura, entretanto, faltava-lhes formação acadêmica. Com o objetivo de promover a educação escolar indígena específica, diferenciada e que atendesse às necessidades culturais de cada comunidade, declarou-se ser de extrema importância que "[...] os profissionais que atuam nas escolas pertençam às sociedades envolvidas no processo escolar" (BRASIL, 1999, p. 12), uma vez que envolve a questão do bilinguismo, a elaboração de materiais didáticos em consonância com a cultura e com a realidade sociolinguística da comunidade, os etnosaberes que possibilitam, além da revitalização da cultura, atribuir significado aos diferentes conteúdos curriculares que contemplam o currículo.

Por meio de pesquisa qualitativa e quantitativa cuja metodologia se fez em levantamentos bibliográficos e documentais organizamos esse texto em duas partes: na primeira abordaremos como vem ocorrendo a formação inicial dos professores indígenas no Paraná por meio do magistério indígena, a nível médio, e pela política de ação afirmativa na educação superior; na segunda parte realizamos uma reflexão e análise dos avanços e 
conquistas indígenas e dos desafios a serem enfrentados pelo estado para uma formação inicial de professores indígenas intercultural e bilíngue, em consonância com os direitos educacionais dos povos indígenas.

\section{O estado do Paraná e as ações para a formação inicial de professores indígenas}

Os movimentos sociais indígenas ocorridos, com grande visibilidade, a partir dos anos de 1970 e no período de redemocratização do país, contribuíram para que seus direitos fossem contemplados no texto da constituinte, sendo reafirmados em legislações posteriores. Nesse sentido, cursos de formação inicial para professores indígenas passam a ser criados "com a intenção de romper com a prática secular de atuação de professores 'brancos' em contextos indígenas, tendo em vista a demanda do movimento indígena por protagonismo e 'assunção de autoria' em seus projetos de sociedade" (NASCIMENTO, 2017, p. 61).

A partir das conquistas constitucionais, em 1993 publica-se as Diretrizes para a Política Nacional de Educação Escolar Indígena, uma das primeiras legislações específicas da educação escolar indígena e que contempla discussões e recomendações para atender às diferentes realidades indígenas no país. No que diz respeito à formação de professores, as Diretrizes afirmam que "as comunidades indígenas exigem, e têm direito a isso, que sejam índios os professores de suas escolas" (BRASIL, 1994, p. 21). Considerando que as escolas indígenas possuem especificidades em relação às línguas, cultura e modos próprios de ensino e aprendizagem, o documento define como questões fundamentais e imprescindíveis a serem contempladas, a saber:

A formação de índios como pesquisadores de suas próprias línguas, história, geografia, meio ambiente, saúde [...];

A formação de índios como alfabetizadores em suas línguas maternas;

A formação de índios como escritores e redatores de material didáticopedagógico em suas línguas maternas, referente aos etnoconhecimentos de suas sociedades;

A formação de índios como professores de português como segunda língua, e redatores de materiais didáticos-pedagógicos em português;

A capacitação de índios como administradores e gestores de seus processos educativos escolarizados (BRASIL, 1994, p. 21).

Diante da necessidade de formação de professores, a Lei de Diretrizes e Bases da Educação LDBEN 9394/96, no Art. 79, garantiu que a "União apoiará técnica e financeiramente os sistemas de ensino no provimento da educação intercultural às comunidades indígenas, desenvolvendo programas integrados de ensino e pesquisa" (BRASIL, 1996) e que deverá incluir nos Planos Nacionais de Educação programas de 
formação de pessoal especializado. O Plano Nacional de Educação (PNE 2001-2010) dedicou o capítulo nove à Educação Indígena, e apresentou como uma das metas o reconhecimento do magistério indígena e a criação da categoria de professores indígenas como carreira específica do magistério.

No Paraná, de acordo, com Cremoneze, De George e Marschner (2006), a primeira turma de formação de professores indígenas, em nível médio - magistério, iniciou em 2006 atendendo às necessidades das comunidades, em consonância com as políticas públicas destinadas aos povos indígenas. Até 2010 foram formados 90 professores das etnias Kaingang e Guarani no Magistério Indígena (MENEZES, 2016). Em 2014, foi autorizado, pelo Parecer CCE/CEMEP n. 96/14, mais uma oferta para o curso de formação de docentes indígenas, na modalidade normal, a nível médio: esse curso iniciou em 2019 no Centro Estadual de Educação Profissional (CEEP), município de Manoel Ribas, Paraná. A formação vem ocorrendo em duas turmas com 35 estudantes cada, sendo uma da etnia Guarani e outra da etnia Kaingang.

Ambas as ofertas de cursos foram organizadas em alternância (BRASIL, 1996). Essa metodologia de organização do ensino, denominada por Cordeiros, Reis e Hage (2011, p. 116) de Pedagogia da Alternância, vem sendo usada em cursos de formação aos jovens e adultos do campo, "visto ser esta uma proposta pedagógica e metodológica capaz de atender as necessidades da articulação entre escolarização e trabalho, propiciando a esses indivíduos o acesso à escola sem que tenham que deixar de trabalhar". As propostas seguiram as orientações dos Referenciais para a Formação de Professores Indígenas (BRASIL, 2000), contemplando na estrutura curricular conteúdos sobre os direitos dos povos indígenas presentes na legislação, o reconhecimento e valorização das culturas, das línguas, das tradições e reflexões acerca da função da escola em comunidades indígenas.

Em 2006, quando iniciou a primeira turma de formação docente indígena no Paraná, segundo levantamento feito por Faustino (2006, p. 243), havia "27 escolas, sendo três estaduais, 23 municipais e uma construída pelos Guarani Nhandewa”. Em relação ao número de matrículas, a autora identificou "cerca de 3300 alunos", e que nessas escolas atuavam "150 professores, sendo 67 não-índios, 65 indígenas da etnia Kaingang e 18 da etnia Guarani”.

Em 2016, após 10 anos de realização desse levantamento, Menezes (2016), com base nas informações disponíveis no site do governo do estado do Paraná (dia a dia da educação), apresentou os seguintes dados em relação à educação básica indígena: 38 escolas estaduais; 5.340 matrículas; 686 professores dos quais 227 indígenas e 459 não indígenas; 38 diretores, sendo 3 indígenas e 35 não indígenas; 4 diretores auxiliares, 1 indígena e 3 não indígenas; 55 
pedagogos, 7 indígenas e 48 não indígenas, 16 coordenadores de ciclo básico (anos iniciais), 5 indígenas e 11 não indígenas.

No ano de 2020, a Educação Básica Indígena no estado do Paraná é formada por 39 escolas situadas em 32 Terras Indígenas habitadas por indígenas das etnias Kaingang, Guarani e Xetá. As Terras Indígenas estão localizadas em 25 municípios do estado, que geralmente apresentam baixo Índice de Desenvolvimento Humano (IDH), e as escolas são jurisdicionadas por 14 núcleos regionais de educação, conforme a localidade (PARANÁ, 2020). Há um total de 5.662 matrículas. As escolas contam com profissionais indígenas e não indígenas, sendo que, no total, 325 professores são indígenas e 439 professores não indígenas. Além dos professores indígenas que atuam nas escolas indígenas, há 24 que ministram aulas de língua indígena, em contraturno: guarani e/ou kaingang, em 16 aldeias/tekohas, atendendo cerca de 300 crianças. Totaliza no estado 349 professores indígenas e 439 professores não indígenas, resultando em 788 professores na educação básica indígena (PARANÁ, 2020).

Alguns indígenas estão assumindo as equipes pedagógicas das escolas, que são formadas por professor pedagogo (com licenciatura em pedagogia) e coordenador do ciclo básico de 4 anos (técnico pedagógico do qual não se exige curso de graduação). São 56 pedagogos, sendo 12 indígenas e 44 não indígenas; e 18 coordenadores de ciclo básico 4 anos, 5 indígenas e 13 não indígenas.

Há ainda a função de direção. Nas 39 escolas existentes no Paraná há 35 diretores nãoindígenas e 4 indígenas. Os/as quatro indígenas que estão na direção são duas formadas em Pedagogia pela Universidade Estadual de Maringá (UEM), um formado em História pela Universidade do Norte do Paraná (UENP) e outra formada em Pedagogia, também pela UENP. Na concepção da gestão democrática, um gestor/diretor/a indígena tem importante papel para o desenvolvimento de ações e decisões coletivas (BAYER; FLORENTINO; ORZECHOWSKI, 2020), visando à melhoria da educação intercultural bilíngue.

A quase totalidade dos professores indígenas no Paraná atuam na educação infantil e nos anos iniciais do ensino fundamental, pois não tem formação em licenciaturas diversas para assumirem os anos finais do ensino fundamental e o ensino médio. A formação de professores tem sido uma das demandas centrais dos movimentos indígenas em todo o país.

Há experiências em diferentes regiões do país e uma política nacional de incentivo à formação de professores, por meio do Programa de Apoio à Formação Superior e Licenciaturas Indígenas (PROLIND), que atende demandas de projetos específicos para cursos superiores. Há, ainda, políticas de Ação Afirmativa com oferta de vagas suplementares ou cotas nas IES (NOVAK, 2014). 
O Prolind foi instituído em 2005, em consonância com o desenvolvimento do Programa Diversidade na Universidade (PDU), iniciado em 2002, conforme pontua Novak (2014). A esse respeito, Nascimento (2017, p. 57) destaca que o "movimento em torno do PDU resultou na criação de condições institucionais, no âmbito do MEC, para o tratamento da diversidade através da formulação de políticas, programas e ações de promoção de uma maior equidade educacional", que oportunizou a criação da Secretaria de Educação Continuada, Alfabetização e Diversidade (SECAD), e entre as iniciativas do PDU, a "criação do Prolind em uma ação conjunta de duas secretarias do MEC, a Secad e a Secretaria de Educação Superior (SESu)" (NASCIMENTO, 2017, p. 61).

As primeiras experiências de Vestibular Diferenciado para ingresso dos povos indígenas nas universidades, em cursos específicos, são do final dos anos de 1990, consolidadas em política de estado em 2001 no Mato Grosso com o primeiro curso de licenciatura indígena, pela Universidade do Estado de Mato Grosso (Unemat), seguida, em 2003, pela criação de um curso de licenciatura indígena, pela Universidade Federal de Roraima, em um cenário de grandes movimentos indígenas para a ampliação e oferta de formação de professores indígenas.

As licenciaturas são organizadas em tempos e espaços diferentes, uma vez que os estudantes são professores que atuam em escolas indígenas, muito semelhantes à organização pela Pedagogia da Alternância, possibilitando a inclusão de grupos indígenas na educação superior pública com fomento do Governo Federal. Os documentos e a ampla legislação sobre essa temática evidenciam que essa formação busca articulação com as secretarias de educação dos estados, organizações indigenistas, instituições de ensino superior, Funai e com o próprio MEC, que regula e avalia os cursos superiores.

Outras formas de ingresso indígena no ensino superior público também vêm ocorrendo. Em atendimento às constantes reivindicações das lideranças indígenas junto à Assessoria Especial para Assuntos Indígenas no estado do Paraná, foi criada, em 2001, uma política de acesso indígena às universidades públicas, por meio da Lei $n^{\circ} 13.134 / 2001$, que destinou três vagas em cada uma das sete IES públicas estaduais e, posteriormente, sua substitutiva, a Lei n. ${ }^{\circ}$ 14.995/2006, que duplicou o número de vagas, passando para seis. Desse modo, vem ocorrendo, desde 2002, o vestibular específico aos povos indígenas (RODRIGUES; WAWZYNIAK, 2006; NOVAK, 2014). Nesta política, desde 2002, ocorre o vestibular indígena, estando, atualmente, em sua XIX edição, e, de acordo com as vagas ${ }^{4}$ 
oferecidas nas sete universidades estaduais e na Universidade Federal do Paraná, houve cerca de 700 matrículas de indígenas em diferentes cursos superiores; conforme dados apresentados no Relatório do Vestibular dos Povos Indígenas, existem 131 indígenas formados no Paraná (CUIA, 2019), totalizando a formação de cerca de $20 \%$ dos ingressantes indígenas no período de 19 anos.

De acordo com a Resolução n. 1, de 7 janeiro de 2015, que instituiu as Diretrizes Curriculares Nacionais para a Formação de Professores Indígenas em cursos de Educação Superior e de Ensino Médio, a formação de professores indígenas "deverá ser realizada em cursos específicos de licenciaturas e pedagogias interculturais" garantindo "a formação inicial em serviço" (BRASIL, 2015, p. 2).

Nesse sentido, está em andamento, no Paraná, uma turma de graduação em Pedagogia Indígena, destinada a indígenas das etnias Kaingang, Guarani e Xetá. Conforme consta no Projeto Político Pedagógico, o curso é "resultado do trabalho de produção coletiva de muitos sujeitos" (PROJETO, 2019, p. 7), iniciando pelos indígenas da comunidade do Rio das Cobras, que apresentaram a demanda de formação à Universidade Estadual do Centro Oeste (Unicentro), que prontamente atendeu e mobilizou junto às lideranças, diretores e professores indígenas, pesquisadores de outras IES, Núcleo Regional de Educação, Funai e outros parceiros, a oferta de 3 turmas, o que totalizará 180 vagas para formar pedagogos/as a fim de que estes possam assumir a docência nas escolas indígenas, uma vez que a demanda de pedagogo/as é significativa no estado.

Mencionamos, por exemplo, a realidade de uma escola indígena no Paraná, localizada na Terra Indígena Ivaí, município de Manoel Ribas, no que diz respeito ao número de matrículas e ao campo de atuação do pedagogo/a. Atualmente, nesta instituição, que atende todas as etapas da educação básica, há 745 matrículas; os espaços que requerem formação específica em curso de graduação em pedagogia são para regência na educação infantil, anos iniciais do ensino fundamental e na função de coordenador pedagógico, que no Paraná é denominado de professor pedagogo/a (PARANÁ, 2020). Esta única escola indígena situada na TI Ivaí comporta 24 professores com graduação em pedagogia para atuarem na educação infantil e anos iniciais do ensino fundamental e cinco professores pedagogos/as para compor a

Universidade Estadual de Maringá (UEM) e Universidade Estadual do Oeste do Paraná (UNIOESTE). Em 2003 a Universidade Estadual do Paraná (UNESPAR) passou a fazer parte. Em 2005, inseriu-se a Universidade Federal do Paraná (UFPR) ofertando 5 vagas, 7 vagas em 2007, e a partir de 2009, 10 vagas. Em 2006, a Lei Estadual $n^{\circ} 14.995 / 2006$ ampliou o número de vagas para 6. E, em 2007, a Universidade Estadual do Norte do Paraná (UENP) se inseriu no programa. Ao todo são seis universidades estaduais, cada uma ofertando seis vagas por edição de vestibular, e uma universidade federal que a partir de 2009 passou a ofertar 10 vagas (RODRIGUES; WAWZYNIAK, 2011; NOVAK, 2014). 
equipe pedagógica da escola. Isto quer dizer que, somente nessa escola, há 29 vagas de atuação para formados em pedagogia (PARANÁ, 2020). Sem grau acadêmico, a grande maioria dos professores indígenas, em salas de aula, atuam como auxiliares, cumprindo a função de intérpretes da língua indígena, pois há comunidades onde as crianças pequenas não falam a língua portuguesa. Outros professores, mesmo sem formação acadêmica, atuam como professores de língua indígena nos anos finais do ensino fundamental e ensino médio.

A partir de dados levantados pela Ação Saberes Indígenas na Escola (MEC/SEMESP), Núcleo UEM-Paraná, e no site dia a dia da educação, no Paraná, atualmente há apenas 68 professores indígenas formados atuando em salas de aulas, e ao todo, há a demanda de 764 professores para atender às 39 escolas indígenas.

Diante desses dados a proposição do curso de Licenciatura em Pedagogia Indígena da UNICENTRO/PR foi organizada pela metodologia da Alternância como importante processo formativo, uma vez que visa atender a legislação vigente, que permite a formação em serviço. Gehrke, Sapelli e Faustino (2019) apontam que os Tempos Educativos (Tempo Universidade e Tempo Comunidade) na pedagogia da alternância aprofundam,

[...] a relação teoria-prática e potencializa o contato com a diversidade étnico-cultural indígena, a vivência de práticas de auto-organização, o intercâmbio com outras comunidades, 0 atendimento imediato às dificuldades de aprendizagem, o acesso a diversificados materiais de estudo, as trocas e novas aprendizagens de técnicas de artesanato, de músicas, de danças, dentre outros elementos culturais (GEHRKE; SAPELLI; FAUSTINO, 2019, p. 12).

Outro aspecto importante a ser destacado refere-se ao currículo do curso. Objetivando uma formação intercultural, o currículo contempla conteúdos de base específica do curso de pedagogia em atendimento às "Diretrizes curriculares nacionais para a formação dos professores de Educação Básica, em nível superior, curso de licenciatura, de graduação plena" (BRASIL, 2006) e conteúdos "relativos às políticas socioeducacionais e aos direitos indígenas, tendo em vista a complexidade e a especificidade do funcionamento, da gestão pedagógica e financeira, bem como do controle social da Educação Escolar Indígena" (BRASIL, 2015, p. 4).

A proposição e efetivação do curso de Pedagogia Indígena assumido pela UNICENTRO, em parceria com outras IES estaduais, tem permitido reflexões que estão possibilitando a organização de novos cursos de licenciatura em conformidade com a demanda dos povos indígenas do estado e a realidade de suas escolas.

RIAEE - Revista Ibero-Americana de Estudos em Educação, Araraquara, v. 16, n. esp. 1, p. 910-925, mar. 2021. e-ISSN: 1982-5587 


\section{Os avanços e desafios na formação de professores indígenas no Paraná}

Embora seja recente uma política específica de formação inicial de professores indígenas no Brasil (NOVAK, 2014), entendemos que houve avanços em nível federal e em nível estadual, como no Mato Grosso, que foi o primeiro estado a iniciar uma oferta de vagas específicas para formação superior indígena. Com Vestibular Específico, desde 2001, o estado já formou cerca de 500 professores de diferentes etnias em cursos de licenciatura intercultural.

No Paraná, a política de inclusão indígena iniciada no mesmo período, pela Lei 13.131/2001, com Vestibular Específico envolvendo todas as IES estaduais públicas e a UFPR, formou, até o presente momento, cerca de 60 professores. Nesse sentido, verifica-se que há a necessidade, urgente, de ampliar essa formação, visando aumentar o número de professores indígenas nas escolas do estado e fomentar tanto a educação intercultural como as línguas indígenas, que se encontram cada vez mais ameaçadas.

O governo do Paraná aprovou leis e implantou a política de vagas suplementares, tendo garantido a realização de vestibulares específicos aos povos indígenas e Bolsa Auxílio aos estudantes, cujos valores são periodicamente atualizados (PARANÁ, 2016), para que estes tenham condições objetivas de estudar. Há, ainda, a oferta de cursos de Magistério Indígena, de nível médio, visando à formação de professores para a educação infantil e anos iniciais nas escolas indígenas. Porém, permanece em descoberto a formação bilíngue e intercultural de professores para atuarem nos anos finais e ensino médio indígenas, bem como, para aturarem como pedagogos/as nas equipes escolares.

Além das 7 IES estaduais, o estado do Paraná conta com 4 universidades federais e um instituto federal com 25 campus avançados (BRASIL, 2020). Essas instituições têm atendido à lei de cotas, n. 12.711/2012, o que possibilita a alguns indígenas ingressarem, também, em cursos superiores e tecnológicos por elas ofertados.

Entre as pesquisas realizadas sobre a formação de professores indígenas destaca-se Alves (2017), que analisou o Programa Pibid Diversidade como possibilidade de aperfeiçoar a formação inicial dos estudantes indígenas que cursavam licenciaturas na Universidade Estadual de Maringá no período de 2014 a 2017, cujo acesso se deu por meio da política de vagas suplementares.

Alves (2017) destaca que os acadêmicos tiveram grandes avanços com a formação desenvolvida pelo Pibid Diversidade. Ao analisar os relatos dos estudantes, a autora afirma que a "participação no PIBID-Diversidade possibilitou conhecer melhor a sua própria aldeia, a escola propriamente dita, em situações de ensino aprendizagem" (ALVES, 2017, p. 161) e 
"que os materiais diversificados e diferenciados utilizados na atuação dos bolsistas atraíram de forma significativa a atenção das crianças, auxiliando na apropriação dos conteúdos" (ALVES, 2017, p. 164).

O estudo de Alves (2017) demonstra que programas como o Pibid Diversidade contribuem para que os futuros docentes indígenas aperfeiçoem os conhecimentos e façam a relação da teoria estudada nas disciplinas que compõem o currículo com a prática/realidade das comunidades indígenas, aproximando-se dos princípios da Pedagogia da Alternância.

Jordão (2014), pesquisadora indígena que tem se dedicado a estudar o papel do professor indígena na escola e na educação indígena, apresenta em suas reflexões que um dos objetivos da atual legislação é que a alfabetização ocorra nas duas línguas (indígena e portuguesa); nesse caso, o professor precisa ter o domínio da língua indígena. A autora ressalta que quando o professor tem o domínio da língua indígena "estariam afastadas muitas das dificuldades do processo de ensino e aprendizagem" e seria também "uma forma de aprender mais sua própria língua pesquisando com os mais velhos da aldeia. Com o estudo da própria língua, os indígenas recuperam metodologias próprias, saberes, fazeres, configurando assim a recuperação da tradição" (JORDÃO, 2014, p. 7).

Podemos considerar que o domínio da língua indígena é um dos desafios a serem enfrentados, uma vez que muitos povos deixaram de falar suas línguas, isso porque ao longo de mais de 500 anos de colonialismo houve períodos na história da educação indígena em que regulamentações legais proibiam o uso da língua indígena (BRASIL, 1845), ou ainda que sutilmente induziram os índios a falar e usar a língua portuguesa (BRASIL, 1973).

A revitalização da cultura, o fortalecimento da língua indígena e a interlocução tornase, portanto, um desafio a ser enfrentado em cursos e/ou programas específicos para a formação inicial de professores indígenas, considerando a especificidade da educação intercultural, diferenciada e bilíngue em que se baseia a "categoria escola indígena" (BRASIL, 1999); nesse sentido, em consonância com os textos legais, o professor indígena é, por fazer parte da comunidade e ter o conhecimento da cultura e da língua indígena, quem tem melhores condições de assumir os processos de ensino e aprendizagem nas escolas indígenas.

A atuação do professor indígena busca, em conjunto com sua comunidade, garantir as características próprias da escola indígena, que são: calendário diferenciado; metodologias que valorizem e incorporem saberes e práticas tradicionais de cada povo; ensino e aprendizagem da língua indígena e da língua portuguesa em suas formas oral e escrita; construção de material didático em consonância com a língua falada e com a organização sociocultural de cada povo; currículo que contemple conteúdos universais e saberes da cultura 
indígena, a compreensão dos processos próprios de aprendizagem das crianças e jovens que frequentam as escolas, gestão que possibilite a construção de projetos pedagógicos com autonomia e especificidade da escola indígena, pois a gestão e organização da escola indígena deve considerar

[...] suas estruturas sociais; suas práticas socioculturais, religiosas e econômicas; suas formas de produção de conhecimento, processos próprios e métodos de ensino-aprendizagem; o uso de materiais didático-pedagógicos produzidos de acordo com o contexto sociocultural de cada povo indígena (BRASIL, 2012, p. 8).

Diante dessa realidade em que o professor indígena irá atuar, entende-se o quão complexo, significativo e fundamental é sua formação, e relativamente diferente da formação de professor não indígena. A formação do professor indígena é sempre permeada pela relação entre os saberes ancestrais e seu povo e os conhecimentos ocidentais que ele adquire em cursos superiores e na formação continuada.

O professor indígena é um sábio, sendo capaz de, no coletivo com demais professores, lideranças, mais velhos, rezadores de suas comunidades, desenvolver projetos pedagógicos interculturais e bilíngues e assim contribuir com o fortalecimento das identidades e das línguas indígenas via escola.

\section{Considerações finais}

A formação inicial de professores indígenas é um tema que requer muitos estudos, pesquisas e proposições de programas e cursos específicos a fim de atender os preceitos legais e as demandas das diferentes comunidades indígenas no Paraná.

Com esse texto foi possível verificar que as políticas, nacional e estaduais, de formação de professores indígenas são recentes, entendendo que a sistematização de uma política pública nacional voltada a esse segmento é oriunda, sobretudo, das demandas produzidas pelos movimentos sociais indígenas a partir dos anos de 1970 a 1990.

Os anos 2000 tornaram-se o marco histórico de regulamentação de uma legislação nacional para o ingresso dos indígenas no ensino superior por meio da política de ação afirmativa, pelas licenciaturas interculturais e cotas. No Paraná, em atendimento a essa política geral, implantou-se legislação que garantiu vagas suplementares, regulamentada pelas leis no $13.134 / 2001$ e n. $^{\circ} 14.995 / 2006$.

Pelos estudos realizados, verificamos que para uma formação consistente que atenda às Diretrizes e aos anseios das comunidades se faz necessário uma maior articulação entre as 
especificidades e demandas das escolas indígenas e os cursos de licenciatura em que esses indígenas estão inseridos. Assim, destacamos as conquistas dos povos indígenas junto ao estado do Paraná, no tocante ao acesso ao ensino superior, e defendemos ser fundamental a ampliação dessa política para que se tenha a garantia da formação de professores em cursos interculturais e bilíngues.

Dessa forma, entendemos que a organização de licenciaturas específicas aos povos indígenas é uma demanda que precisa ser discutida com os povos indígenas e executada no estado do Paraná, uma vez que possibilitam um currículo que incorpore conteúdos das culturas e o respeito às formas de aprendizagem dos estudantes indígenas.

Há uma discrepância que afeta diretamente a formação escolar das novas gerações indígenas: ao observar-se que nas 39 escolas estaduais indígenas do Paraná a maioria dos cerca de 800 professores que nelas atuam não são indígenas e que, entre os professores indígenas, $80 \%$ não tem formação superior e nem estabilidade no emprego, pois são contratados por meio de processos simplificados com contratos temporários.

Essa questão remete à urgência em investimentos, tanto financeiros quanto pedagógicos, na formação inicial de professores indígenas, uma vez que o estado apresenta grande demanda de formação de professores indígenas para atuarem nas interculturais, sendo esse um grande desafio, ampliar o número de professores indígenas e ao mesmo tempo a oferta de uma formação de qualidade a fim de contemplar aspectos da cultura e a valorização das línguas maternas nos processos de ensino e de aprendizagem, garantindo assim a função da escola indígena, tema esse que merece aprofundamento.

\section{REFERÊNCIAS}

AGUILERA URQUIZA, A. H.; NASCIMENTO, A. C. Rede de saberes: políticas de ação afirmativa no ensino superior para indígenas no Mato Grosso do Sul. Rio de Janeiro: FLACSO, 2013.

ALVES, R. C. A formação inicial de professores para a docência nas escolas indígenas: o Pibid-Diversidade na UEM-PR. 2017. 230 f. Dissertação (Mestrado) - Programa de PósGraduação em Educação, Universidade Estadual de Maringá, Maringá, 2017.

BAYER, M. F.; FLORENTINO, O. P. M.; ORZECHOWSKI, S. T. Educação escolar indígena: o processo de gestão como forma de organização e respeito aos conhecimentos. Revista Espacialidades, Natal, RN, v. 16, n. 1, p. 39-64, 2020.

BRASIL. Congresso Nacional. Lei n. 6.001, de 19 de dezembro de 1973. Dispõe sobre o Estatuto do Índio. Brasília, 1973. Disponível em: http://www.planalto.gov.br/ccivil_03/Leis/L6001.htm. Acesso em: 20 set. 2020. 
BRASIL. Constituição (1988). Constituição da República Federativa do Brasil. 23. ed. Brasília, DF: Senado, 1988.

BRASIL. Decreto n. 26, de 4 de fevereiro de 1991. Dispõe sobre a Educação Indígena no Brasil. Diário Oficial da União: Seção 1, Brasília, DF, n. 25, p. 2487, 5 fev. 1991.

BRASIL. Decreto n. 426, de 24 de julho de 1845. Contêm o Regulamento ácerca das Missões de catechese, e civilisação dos Indios. Brasília, DF: Senado Brasileiro, 1875. Disponível em: http://legis.senado.leg.br/norma/387574/publicacao/15771126. Acesso em: 20 set. 2020.

BRASIL. Ministério da Educação e do Desporto. Diretrizes para a política nacional de educação escolar indígena. Em aberto, Brasília, v. 14, n. 63, p. 175-187, jul./dez. 1994.

BRASIL. Ministério da Educação. Instituições da rede federal. Brasil, DF: MEC, 2020. Disponível em: http://simec.mec.gov.br/academico/mapa/dados_instituto_edpro.php?uf=PR. Acesso em 16 set. 2020.

BRASIL. Resolução CNE/CP n. 1, de 15 de maio de 2006. Institui Diretrizes Curriculares Nacionais para o Curso de Graduação em Pedagogia, licenciatura. Diário Oficial da União: Seção 1, Brasília, DF, p. 11, 16 maio 2006. Disponível em: http://portal.mec.gov.br/cne/arquivos/pdf/rcp01_06.pdf. Acesso em: 19set. 2020.

BRASIL. Resolução n. 1, de 7 janeiro de 2015. Institui Diretrizes Curriculares Nacionais para a Formação de Professores Indígenas em cursos de Educação Superior e de Ensino Médio e dá outras providências. Diário Oficial da União: Seção 1, Brasília, DF, p. 11-12, 8 jan. 2015. Disponível em:

http://portal.mec.gov.br/index.php?option $=$ com_docman\&view $=$ download\&alias $=16870$-rescne-cp-001-07012015\&category_slug=janeiro-2015-pdf\&Itemid=30192. Acesso em 19 set. 2020.

CORDEIRO, G. N. K.; REIS, N. S.; HAGE, S. M. Pedagogia da alternância e seus desafios para assegurar a formação humana dos sujeitos e a sustentabilidade do campo. Em Aberto, Brasília, v. 24, n. 85, abr. 2011. p. 115-125.

CREMONEZE, C.; DE GEORGE, I. T. B.; MARSCHNER, R. Formação de professores indígenas no estado do Paraná: breve histórico. In: PARANÁ. Educação escolar indígena. Curitiba: SEED, 2006.

CUIA. Comissão Universidade para os Índios. Relatório do vestibular dos povos indígenas. Superintendência Geral de Ciência, Tecnologia e Ensino Superior, Curitiba, 2019.

FAUSTINO. R. C. Política educacional nos anos de 1990: o multiculturalismo e a interculturalidade na educação escolar indígena. 2006. 329 f. Tese (Doutorado em Educação) - Programa de Pós-Graduação em Educação, Universidade Federal de Santa Catarina, Florianópolis, 2006. 
GEHRKE, M.; SAPELLI, M. L. S.; FAUSTINO, R. C. A formação de pedagogos indígenas em alternância no Paraná: uma contribuição à interculturalidade e ao bilinguismo. Revista Brasileira de Educação do Campo, v. 4, p. 1-26, 2019.

JORDÃO, E. L. P. Reflexões sobre o papel do professor indígena na educação escolar indígena e educação indígena. Web revista página de debate: linguística e linguagem, Campo Grande, n. 23, p. 1-14, jul. 2014.

MENEZES, M. C. B. A política de educação escolar indígena e o processo de alfabetização em uma comunidade Kaingang no Paraná. 2016. 244 f. Tese (Doutorado em Educação) - Programa de Pós-Graduação em Educação, Universidade Estadual de Maringá, Maringá, 2016.

NASCIMENTO, R. G. Educação superior de professores indígenas no Brasil: avanços e desafios do programa de licenciaturas interculturais indígenas. In: Educación superior y pueblos indígenas y afrodescendientes en América Latina. Venezuela: UNESCO/IESALC, 2017. Colección 25, v. 20, p. 49-76.

NOVAK, M. S. J. Os Organismos internacionais, a educação superior para indígenas nos anos de 1990 e a experiência do Paraná: estudo das ações da Universidade Estadual de Maringá. 2014. 342 f. Tese (Doutorado em Educação) - Programa de Pós-graduação em Educação, Universidade Estadual de Maringá, Maringá, 2014.

OLIVEIRA, S. M. Formação de professores indígenas bilíngues: a experiência Kaingang. 1999. Dissertação (Mestrado) - Centro de Educação, Universidade Federal de Santa Catarina, Florianópolis, 1999.

PARANÁ. Dia a dia da educação. Consulta escolas, Curitiba, 2020. Disponível em: http://www.consultaescolas.pr.gov.br/consultaescolasjava/pages/templates/initial2.jsf?windowId=ac4. Acesso em: 20 mar. 2020.

PARANÁ. Resolução n. 023/2016. Curitiba, PR: Secretaria de Estado da Ciência, Tecnologia e Ensino Superior, 2016.

PROJETO Político Pedagógico do Curso de Pedagogia: formação intercultural e bilíngue de professores indígenas no Paraná. Guarapuava, PR: Unicentro, 2019. v. 9. (Caderno de Educação do Campo)

RODRIGUES, I. C.; WAWZYNIAK, J. V. Inclusão e permanência de estudantes indígenas no ensino superior público no Paraná - reflexões. Programa de ações afirmativas, São Carlos, SP: Universidade Federal de São Carlos, 2006. Disponível em: http://www.acoesafirmativas.ufscar.br/arquivos. Acesso em: 19 set. 2020. 


\section{Como referenciar este artigo}

MENEZES, M. C. B.; FAUSTINO, R. C.; NOVAK, M. S. J. Formação inicial de professores indígenas: ações desenvolvidas no estado do Paraná. Revista Ibero-Americana de Estudos em Educação, Araraquara, v. 16, n. esp. 1, p. 910-925, mar. 2021. e-ISSN: 1982-5587. DOI: https://doi.org/10.21723/riaee.v16iEsp.1.14928

Submissão em: 20/06/2020

Revisões requeridas em: 16/09/2020

Aceito em: 03/11/2020

Publicado em: 01/03/2021 